\title{
Making the Chinese Copycat: Trademarks and Recipes in Early Twentieth- Century Global Science and Capitalism
}

\author{
by Eugenia Lean*
}

\begin{abstract}
This essay examines early twentieth-century international disputes over alleged Chinese copying of the trademarks and brand recipes of Burroughs Wellcome and Company's Hazeline Snow vanishing cream. By doing so, it explores the complex backand-forth that occurred between metropole manufacturers and actors in the colonial periphery in negotiating the parameters of a newly emerging global trademark regime. The essay does not present Chinese adapters of brand trademarks and recipes as simply unethical counterfeiters or passive victims of imperial aggression but treats them as full participants in a global debate over questions of ownership of commercial marks and manufacturing and chemical knowledge. Furthermore, because of Chinese adaptation of marks and circulation of brand recipes as "common knowledge," Burroughs Wellcome and Company mobilized the trademark law of the newly emerging industrial property regime to halt the travel of adapted marks and recipes. The company's deployment of trademark law thus serves as an example of how a capitalist corporation sought to ensure its advantage in competitive pharmaceutical markets by obstructing the purportedly "free markets" of capitalism and to stymie any open circulation of chemical and manufacturing knowledge. Such findings allow us to refine the recent emphasis on "circulation" often used in the historical analysis of modern science and capitalism.
\end{abstract}

\section{AUDACIOUS FRAUD EXPOSED}

Chinese Imitation of "'Hazeline' Snow”

After prolonged investigations, all members of a gang of Chinese (six in number) have been convicted on a charge of forging the Trade Mark " "Hazeline' Snow." A most elaborate fraud, in which pots, labels and advertising matter were slavishly copied, has thus been exposed. Fines amounting to 600 dollars and terms of imprisonment ranging from four to six months have

\footnotetext{
* Department of East Asian Languages and Cultures, Columbia University, New York, NY 10027; ey12006@columbia.edu.

Thanks to William Deringer, Lukas Rieppel, Paize Keulemans, and two anonymous reviewers for reading drafts of this essay. I would also like to thank participants at the "Science and Capitalism: Entangled Histories" conference, sponsored by the Weatherhead East Asian Institute, the Center for Science and Society, the Society of Fellows, and the Heyman Center at Columbia University, and the audiences at related talks that I have given at Tel Aviv University, MIT, and National Taiwan University.
}

- 2018 by The History of Science Society. All rights reserved. 0369-7827/11/2018-0014\$10.00

OSIRIS 2018, $33: 271-293$ 
been imposed. Fraudulent packages have been confiscated and plates, etc., destroyed.

-Burroughs Wellcome and Company announcement, ca. $1923^{1}$

Recently, some have conducted research on Hazeline Snow to determine what it contains. To manufacture it, one only needs to mix the following ingredients, hazeline, stearic acid, glycerin, sodium bicarbonate and soda water. This is the [manufacturing] method. Because the procedure is slightly complicated, ... . it has not been well understood.

-From "Method for Manufacturing Cosmetics," $1915^{2}$

In 1892, Burroughs Wellcome and Company (hereafter BW\&C) ${ }^{3}$ introduced Hazeline Snow, the first commercial stearate cream. ${ }^{4}$ The company boasted that witch hazel extract, a key ingredient in the product, could treat a range of ailments. According to one 1912 BW\&C advertisement, the witch hazel extract could be "prescribed in cases of haemorrhage from the nose, lungs, womb, rectum, \&c. Is a valuable agent in the treatment of bruises, sprains, inflammation, peritonitis, piles, fistula, anal fissure, ulcers, varicose veins, eczematous surfaces, tonsillitis pharyngitis, nasal and post-nasal catarrh, stomatitis, leucorrhoea, nasal polypi, \&c." ${ }^{\prime}$ The vanishing cream was considered a toiletry item that was also medicinal. It was sold in Britain and abroad. Given its immediate and far-reaching success, both the cream's trademark and its manufacturing recipe were widely copied and circulated. ${ }^{6}$ To stem the widespread imitation, BW\&C pursued alleged copiers around the world through a globally emerging trademark regime. Yet as we see here, the Chinese copier in particular caught BW\&C's attention. By reviewing trademark disputes between BW\&C and alleged Chinese copycats, this essay sees these disputes not merely as a matter of law, but instead as instances of global entanglements over issues of ownership and copying of both brand names and manufacturing formulas. In turn, these debates over exactly what constituted ownership and industrial property gained pointed geopolitical significance. In counterfeiting brand marks and unapologetically circulating brand recipes and their manufacturing knowledge as "common knowledge," persistent Chinese copiers earned the wrath of companies like BW\&C in part because their actions threatened to expose how BW\&C and similar companies sought to impede the circulation of chemical and manufacturing knowledge in order to promote asymmetric accumulation of capital in their favor. By defiantly casting BW\&C brand recipes as common knowledge, Chinese adapters fundamentally challenged the globalizing pretensions of imperial science by exposing how brand rec-

\footnotetext{
${ }^{1}$ This announcement can be located among a collection of Burroughs Wellcome and Co. announcements featuring manufacturers around the world that the company had caught in what it perceived to be fraudulent use of its marks. This one is item 16. See Wellcome Library, Special Collection, WF/L/06/ 097.

${ }^{2}$ Shen Ruiqing, "Method for Manufacturing Cosmetics," Funü zazhi 1 (May 1915): 18-25, on 25.

${ }^{3}$ Burroughs Wellcome \& Co. was also known as the Wellcome Foundation Limited. Henry Wellcome and Silas Burroughs founded BW\&C in 1880 as a pharmaceutical company. BW\&C started to expand overseas at the turn of the century and by 1912 had a branch in Shanghai.

${ }^{4}$ See Cosmetics and Skin's "Hazeline' Snow" page, http://www.cosmeticsandskin.com/aba/hazeline -snow.php (accessed 21 February 2016).

5 Ibid.

${ }^{6}$ BW\&C obtained registration for the "Hazeline' Snow" trademark on toilet goods in the British Patent Office on 7 October 1903. The imagery, consisting of a snow-capped mountain, a stream, a tree, and rocks and featured on Hazeline Snow packaging, was trademarked on 24 October 1904. See Patent and Trade Mark Review 17 (December 1918): 25.
} 
ipes (and their chemical and manufacturing know-how) were treated as objects of property to be jealously guarded and owned only by proper corporate agents, and not as vehicles that share and circulate scientific knowledge openly.

Adaptation of BW\&C trademarks and packaging and the circulation of its brand recipes occurred worldwide. To stem this tide of global copying, BW\&C and other British and multinational pharmaceutical companies worked in conjunction with their governments to erect a global regime of industrial property rights that turned on both trademark law and convention. Trademark infringement laws were meant to curb not only any fraudulent use of trademarks but also the unauthorized circulation of recipes. Because recipes for patent medicines and cosmetics tended to be straightforward prescriptions of how to assemble ingredients rather than the creation of new chemical compounds and materials, they were not subjected to patent protection. Pharmaceutical companies like BW\&C thus protected their manufacturing recipes by branding them and targeting their unapproved circulation as violations of brand infringement.

If copying of Hazeline Snow occurred in all corners of the world, the Chinese counterfeiter quickly came to assume the dubious distinction of being a particularly egregious perpetrator. By the 1910s, Hazeline Snow advertisements were appearing with regularity in Chinese journals and newspapers. Almost as quickly, Chinese copycats started attracting BW\&C's attention. As the first epigraph above suggests, by the 1920 s, BW\&C was painting Chinese merchants as "audacious" in their counterfeiting of Hazeline Snow's trademark and assorted packaging. The question of how and why the "Chinese copycat" came to occupy such a prominent position in the global imaginarium of the twentieth century, is a central concern of this essay. BW\&C's targeting of Chinese merchants as consummate perpetrators of fraud stemmed in part from the vibrant and unruly copying that was indeed taking place in China. But, as this essay argues, the attempt to discipline domestic offenders infringing in the British pharmaceutical company's own backyard was just as significant a reason. By contrasting legitimate British merchants with audacious Chinese committers of fraud, companies like BW\&C sought to identify an effective foil against which they could define the parameters of proper commercial behavior and pursue alleged counterfeiters both in their own country and abroad. The venal Chinese copycat was effectively marshaled to defend a modern intellectual property (IP) regime that would only further the interests of British firms. ${ }^{7}$ By creating the "Chinese counterfeiter," BW\&C was implicitly identifying itself (and like-minded players) as the legitimate purveyor of sanctioned products and knowledge.

If imperialist interests informed how BW\&C and other Western actors promoted modern trademark infringement and targeted alleged Chinese copiers, the Chinese were hardly passive victims. Rather, they engaged with the emerging new property rights regime in complex ways. To start, "the Chinese" were a heterogeneous group, pursuing a variety of interests through issues of duplication, infringement, and ownership. If they

\footnotetext{
${ }^{7}$ By identifying the rise of the Chinese copycat in an era of modern capitalism and science, my essay provides a parallel case example to Lee Vinsel's contribution to this volume, which sheds light on the constitution of the "accident-prone driver." In both cases, we see how new identities are created in part as a foil against which to secure certain capitalist interests. If the Chinese copycat functioned to justify a trademark regime that would advance imperialist industrial interests like BW\&C, in Vinsel's case, the accident-prone driver was mobilized to exonerate auto manufacturers from accountability in instances of automative injury and death. See Vinsel, "'Safe Driving Depends on the Man at the Wheel': Psychologists and the Subject of Auto Safety, 1920-55," in this volume.
} 
did not always perceive "copying" as an act of infringement, they cannot simply be understood as exceptionally unethical perpetrators, as much of the conventional Westbased legal narrative that was emerging at the time (and that persists into the contemporary period) would have it. Nor were they mere victims of an imperialist conspiracy, as Chinese nationalist interpretations continue to claim. ${ }^{8}$ At times, they acted in concert against British merchants. At times, they were a fractured, diverse group, pursuing their own individual interests in regard to trademark use and legislation. For certain actors, international tension over the proper use of trademarks could quickly became a matter of imperialism and profoundly violate Chinese sovereignty. For others, trademark regulation was to be pursued domestically. Chinese manufacturers who found their brands and recipes subjected to infringement by copycat firms drew from the evolving trademark regime to present themselves as "modern" industrialists as opposed to traditionmired merchants. And for still others, these matters were simply issues to be worked around, in practical pursuit of profit in their day-to-day operations.

By focusing on how Chinese compilers rendered the recipes for Hazeline Snow and other brand objects as common knowledge, this essay furthermore sheds light on how Chinese "copiers" defied Western corporate interests that sought to universalize certain norms of capitalism and science. As the second epigraph above shows, Hazeline Snow's trademark and packaging were not the only part of the commodity that was being shared in China. The cream's ingredients and related manufacturing tips circulated in the early twentieth-century Chinese press and were indicative of a more general trend whereby manufacturing formulas and the basic chemistry behind the production of both domestic and foreign brand-name patent medicines and toiletry items were printed with little hesitation as "common knowledge" [changshi]. Common knowledge was not "pure" scientific knowledge being pursued in China's newly established academic universities. Nor was it the "Mr. Science" being promoted by highbrow intellectuals in the New Culture Movement (1915-9). Part of the slogan of "Mr. Science and Mr. Democracy," "Mr. Science" was an abstract and lofty notion of universal science that, along with democracy, was identified as one of the pillars to building Chinese modernity. Instead, common knowledge was unapologetically commodified. It was know-how on manufacturing and chemistry and included brand recipes, all of which were disseminated widely in the commercial press. Hardly basic or ordinary, the "common" aspect of common knowledge and its value derived from it being shared without regard to brand ownership. As such, it helped engender the savvy and informed consumer in an era when global capitalism introduced untrustworthy markets into China, filled with faulty, suspect, and even possibly counterfeit goods. It was also crucial for nativist industrialists and budding manufacturers invested in building Chinese industry to compete in a highly competitive global market of cosmetics and pharmaceutics. If such strategic adaptation of manufacturing knowledge and chemical knowledge often defied ideas of trademark infringement being promoted by BW\&C, for Chinese compilers and manufacturers, common knowledge was invaluable.

\footnotetext{
${ }^{8}$ PRC nationalist historiography often views the history of trademarks in China as one of many examples of China's victimization vis-à-vis Western imperialism. See Zuo Xuchu, Zhongguo jindai shangbiao jianshi [The brief history of modern trademarks in China] (Shanghai, 2003), esp. 51-6, who has characterized Western intervention in compiling China's modern Trademark Law in 1923 as an example of Western imperialist encroachment into China.
} 
Like Hallam Stevens's contribution to this volume, this essay historicizes the process by which the modern intellectual property rights (IPR) regime emerged. ${ }^{9}$ In doing so, it challenges the legal conceits of "proper" ownership that have been normalized and institutionalized by that very regime. Legal narratives emerging globally at the turn of the twentieth century were crucial in promoting the idea that trademarks were crucial to help the public avoid confusion in the market, creating and enforcing clarity, and thus were there to protect the interests of the consumers. They have also generated the strong impression that the Chinese copycat was among the most audacious counterfeiters. However, in this study, the politics of empire behind these legal conceits are exposed. The modern trademark regime - and its attendant counterfoil, the Chinese copycat - was a strategic resource used to create and open foreign markets such as China's by eliminating competition for large corporations such as BW\&C. Moreover, trademark law (and IP more generally) was used to cast certain kinds of epistemic and commercial exchange as illegitimate. It functioned to obstruct the free circulation of key knowledge to hobble emerging manufacturers and create favorable conditions for well-established capitalist corporations.

Finally, by shedding light on this dynamic between companies like BW\&C and Chinese copiers, this essay shows that despite uneven relations of global power, actions by Chinese actors impinged, even if unintentionally and obliquely, on the evolving shape of the new regime of trademark infringement and, by extension, the parameters of global capitalism. One might argue that modern IP emerged as it did in ways crucially dependent upon the action of periphery actors like Chinese adapters. Frequent and vibrant, adaptation of both the mark of a brand and its manufacturing know-how in China (and other peripheral locales) spurred BW\&C and related companies to develop and normalize trademark laws. These strategies, and the threat of becoming like the venal Chinese copycat, were in turn used to domesticate local copycats as well. From this perspective, we can better understand why British companies such as $\mathrm{BW} \& \mathrm{C}$ were so invested in propagating the idea of the Chinese copycat. Much of it had to do with compensating for its own considerable lack of control over the situation, both domestically and abroad.

\section{A MARK OF EMPIRE: THE MODERN TRADEMARK AND INDUSTRIAL PROPERTY}

With advances in modern chemistry and industrial manufacturing, the nineteenthcentury world had become saturated to an unprecedented degree with mass-produced near-uniform goods, patent medicines and drugs among the most popular. By the early twentieth century, the rise of a modern drug and pharmaceutical industry that was increasingly predicated on laboratories and clinical science helped render trademarks and patents into what it deemed to be ethically and legally legitimate means to protect both the consumer and the company in ways familiar to us today. ${ }^{10}$ Seeking to sell their prod-

\footnotetext{
${ }^{9}$ Hallam Stevens, "Starting up Biology in China: Performances of Life at BGI," in this volume.

${ }^{10}$ Joseph M. Gabriel, Medical Monopolv: Intellectual Propertv Rights and the Origins of the Modern Pharmaceutical Industrv (Chicago, 2014), 196. In the first decade of the twentieth century, European manufacturers, like the German manufacturer Bayer, led the way in patenting and trademarking drug products. In the United States, manufacturers only started to utilize this new framework by World War I, at which point they began to defend their scientific innovations by pursuing product patents and taking out trademarks to protect their innovation at the level of the product itself. Prior to the first decade of the twentieth century, U.S. manufacturers were ambivalent about the role of trademarks and patents, and many held that both perpetuated unethical forms of monopoly. See also Adrian Johns, $P i$ -
} 
ucts at an unprecedented economy of scale and scope, manufacturers quickly came to regard the modern trademark as an indispensable means to carve out distinction for their product among a sea of indistinguishable or nearly indistinguishable products. It was often difficult, if not impossible, for even the most discerning consumer to determine the quality of the commodity or the danger of the remedy based on the mere appearance of the item. A trademark guaranteeing the reputation of a brand was to aid consumers to make such evaluations. And as the authority of trademarks spread, so too did the copying of trademarks. "Counterfeiting" successful marks and packaging designs, along with adapting brand-name manufacturing recipes, quickly became highly lucrative endeavors that copycats around the world undertook to sell their wares.

The new ways of understanding trademarks were entangled with the politics of empire from the start. By the nineteenth century, regulation and policing of fraudulent claims of ownership were aimed both at domestic (Western metropole-based) copycats and at copycats in far-flung corners of the colonial world. On 20 March 1883, the Paris Convention for the Protection of Industrial Property was signed. As one of the first intellectual property treaties, the convention sought to codify trademark enforcement and criminalize brand infringement globally. As the trademark was presented as a mark of modern capitalism and civilized business practices, large-scale manufacturers of massproduced goods increasingly worked along with their respective governments to deploy mechanisms of international law, diplomatic pressure, and direct force to influence the colonial world to revise indigenous legal systems to abide by and adopt the legal norms and practices that benefited the modern industrial property rights regime. Pharmaceutical companies such as BW\&C and Unilever were particularly aggressive in lobbying their respective governments to utilize legal institutions, political means, and diplomatic channels to police potential fraud around the world. ${ }^{11}$ For them, trademarks were not simply to clarify market confusion but could also serve a more insidious yet crucial function. By demarcating what constituted legitimate goods, they could also be used to obstruct the movement of purportedly illegitimate goods, including those whose "illegitimacy" stemmed from their national origin.

Implementation of this global regime of industrial property rights was not easily achieved. China, in particular, became an ideal site where the emerging system could be vigorously tested and subjected to interrogation and challenge. The early Republic was a period when the central state was exceptionally weak in the face of internecine warfare among militarists and ongoing imperialist pressures. Extraterritoriality in China's treaty ports meant that the political and commercial presence of multiple Western powers and Japan in China served to fragment Chinese political authority and control, as well as that of any single imperialist force. Such fragmentation characterized the commercial sphere as well. Multiple views of brand ownership and product authenticity commingled in China's markets. Competitors from around the world saw their practices and views on proper commercial protocol come into direct conflict with each

racy: The Intellectual Property Wars from Gutenberg to Gates (Chicago, 2009), chap. 5. Johns argues that the first pharmaceutical patent emerged in eighteenth-century Britain, when the medical market grew more anonymous and it was increasingly difficult for consumers to assay the chemical composition of potentially dangerous remedies. The widespread practice of relying on patents, however, did not take root at that point.

${ }^{11}$ Eugenia Lean, "Marking and Copying from Qing to China: Late Imperial Culture in Trademark Infringement Cases of the Early Twentieth-Century" (paper presented at "From Qing to China: Rethinking the Interplay of Tradition and Modernity, 1860-1949," Tel Aviv University, 20-22 May 2012). 
other. The presence of multiple national players competing in China's commercial market also meant that a vibrant and unruly market of goods and things emerged where copying was rampant. Copiers were not just Chinese merchants but consisted of a range of nationalities, all of whom were seeking to carve out advantage in the competitive environment of China's highly cosmopolitan markets. Whether national and provincial officials, alleged copycat companies (Chinese and otherwise), or Chinese consumers, participants on the ground were driven by an array of motivations with respect to trademark infringement. Chinese treaty-port markets were thus in many respects ideal forums for international debates on trademark law, property rights, counterfeiting, and notions of legal ownership of brand and reputation.

In fact, it was precisely this context that made early Republican China an ideal place in which to bring rigorous trademark law into being, rather than the metropole. Timothy Mitchell has argued that modern statecraft emerged in areas of the world that experienced imperialism. Egypt, he claims, was where Great Britain "performed" the modern economy. ${ }^{12}$ The economy as a knowable and quantified entity had to be ontologically conjured and brought into being through technical means (such as national income measures), and because the colonial state did not have enough power to regulate economic activity to the extent it did in the metropole, this conjuring was initially accomplished in the colonial periphery in Egypt. One might see certain parallels in the history of modern IP. It was in China during the unruly "warlord era" where Great Britain honed its modern trademark law, which it billed as a mechanism for bringing order to an unruly and confusing (and thus dangerous) marketplace. In order for legally protected trademarks to be brought into being at home, they first had to be rigorously enforced abroad.

\section{THE EMERGENCE OF THE CHINESE COPYCAT: BW\&C TRADEMARK CASES}

In examining a set of 1910 s and early 1920 s BW\&C announcements regarding the company's prosecution of trademark infringement by its in-house patent office, this section is less concerned with whether Chinese merchants had in fact engaged in fraud. Instead, it uses the alleged copying and the announcements to illuminate what was a global dialogue over what constituted an authentic mark and the nature of its ownership. It considers how in an era of waning yet persistent imperialism in China, Chinese copycats made their presence felt, spurring firms like BW\&C to invest in controlling trademark infringement around the world. The texts reveal how savvy tactics of copying and borrowing by Chinese merchants, along with prevailing Orientalist assumptions in Europe of Chinese corruption and shady business dealings, allowed pharmaceutical companies like BW\&C to render the Chinese "counterfeiter" as a significant foil in their efforts to eradicate domestic British copying. As the uncivilized counterfeiting Other to modern, Western law-abiding merchants, the Chinese copycat became a compelling counterexample. It also came to stand at the center of the making of modern IP.

BW\&C actively promoted and enforced what it deemed to be proper trademark use and practice in a variety of ways (fig. 1). It sought to register its popular marks with newly established administrative institutions throughout the world and acted under

\footnotetext{
${ }^{12}$ See Timothy Mitchell, The Rule of Experts: Egypt, Techno-Politics, Modernity (Berkeley and Los Angeles, 2002).
} 


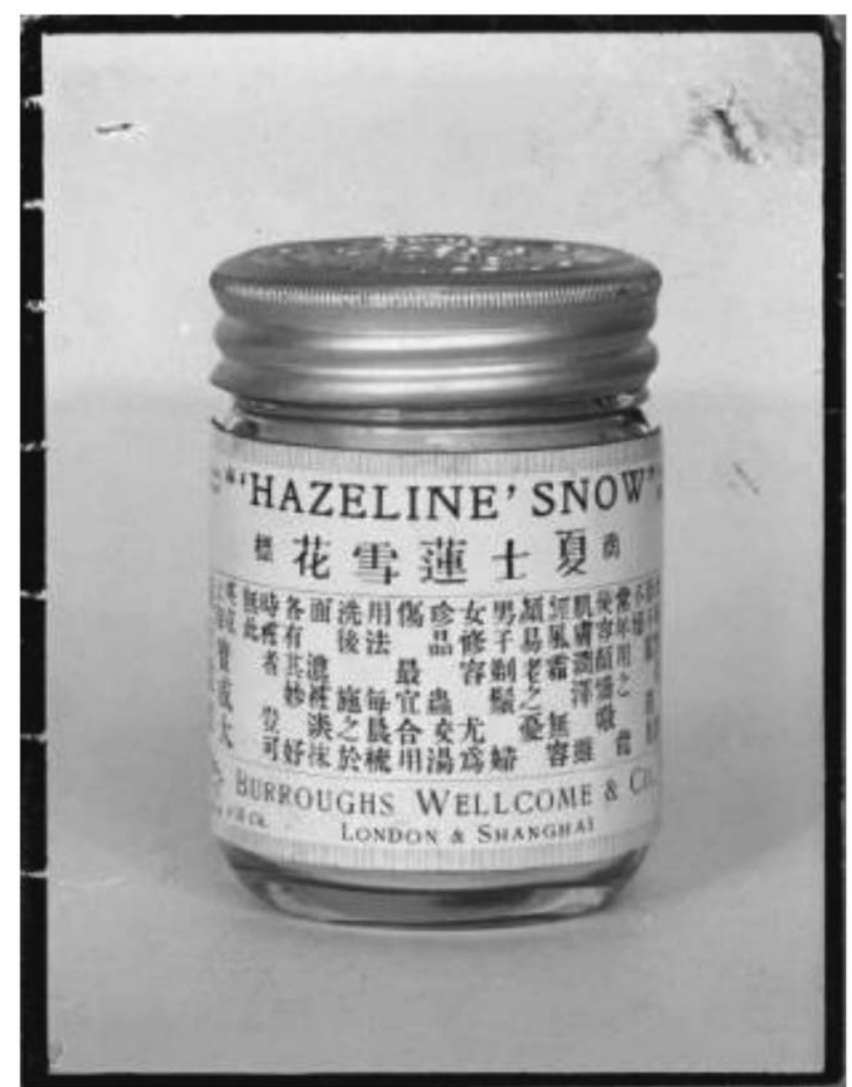

Figure 1. Photograph of an "authentic" BW\&C "'Hazeline' Snow" jar that was sold on the Chinese market around 1923-4. From Wellcome Library London, Archives, Image no. L0050258.

the assumption that these registrations were enforceable through law. ${ }^{13}$ The company also poured resources into policing trademark usage by opening up in-house offices to deal with trademark infringement and patent abuse cases. Run by the Wellcome Foundation secretariat, A. E. Warden, the office monitored markets for brand counterfeiting from London to Bombay and from Ningbo to Johannesburg. It aggressively pursued companies and individuals it perceived as infringing on its trademark, relying on reports of counterfeited products or sending their own representatives to scour stores and markets for look-alike products. ${ }^{14}$ These tactics were fairly effective. From 1917

${ }^{13}$ The earliest registration of a trademark with the word "Hazeline" for the chemical and toilet article classes of goods (class 3) was by BW\&C in the United Kingdom on 10 May 1880 (no. 22,388) and was renewed in 1894. Ensuing registration of BW\&C trademarks with the word "Hazeline" in the United Kingdom took place in the years following. For a review of this history, see a set of legal documents prepared by A. E. Warden, who was in charge of BW\&C's in-house department dedicated to trademark infringement, especially the document titled "Hazeline," 14 March 1907, Wellcome Library, Special Collection, WF/L/06/158.

${ }^{14}$ Monitoring tactics were as prosaic as sending undercover agents into stores suspected of selling items with forged trademarks. BW\& C archives include examples of reports filed by "undercover agents" visiting unsuspecting stores asking for counterfeit products. See, e.g., the memo titled "HAZOL," 22 March 1907, Wellcome Library, Special Collection, WF/L/06/158. 
to 1937 , BW\&C secured over fifteen public apologies for trademark infringement of their brands in Great Britain alone. In the India market they prosecuted at least eleven forgers, and in the Asia market (China, Japan, and Formosa), they acted against at least six. ${ }^{15}$ Most counterfeiters were charged with fraudulently copying either BW\&C's famous trademark "Tabloid" or the brand name and packaging of "Hazeline' Snow."

Once trademark offenders were uncovered, BW\&C's patent office would prosecute the offending firms and publicly announce its success. Such announcements would often include an apology from the copycat company. In the case of the mark or design of the packaging being copied, a picture of the offending version was often positioned next to the original to remind readers of the announcement of the genuine article. These announcements were not necessarily intended to deter copycats in far-flung markets. Written in English, the apologies targeted English-reading audiences and appeared in British trade journals. ${ }^{16}$ Possible audiences for these announcements included fellow British chemical and pharmaceutical companies, small and large, and their publication was meant to reinforce and disseminate domestically (or within the British Empire) the new ideals of trademark and brand ownership.

In order to drive home that these new practices of trademark ownership were emblematic of a modern nation such as Great Britain, having examples of copycat merchants from colonial and semicolonial outposts defying such practices was highly effective. Chinese copycat firms constituted a compelling foil against which these "modern" practices could be articulated. By the nineteenth century, European actors had come to identify Qing China as an empire lacking civilized law, which allowed them to legitimate their extraterritorial claims in China. ${ }^{17}$ The actual situation was much more complicated. In terms of commercial law, although the Qing did not provide much in the way of explicit codified law, it did protect marks through customary practice. ${ }^{18}$ And as guild mechanisms and customary protection of marks worked only for domestic producers, foreign traders and merchants entering into China's markets in the nineteenth

\footnotetext{
${ }^{15}$ For these announcements, see Wellcome Library, Special Collection, WF/L/06/097.

${ }^{16}$ One announcement, "Before the Mixed Court Shanghai: Burroughs Wellcome \& Co. Plaintiffs versus Zing Tsa-nan trading as The Nanyang Medical Co. Defendants," included the image of a newspaper clipping from the 5 April 1919 issue of "The Chemist and Druggist." This clipping announced BW\&C's success in securing a "perpetual injunction" restraining the defendants, the Nanyang Medical Co., from selling "Nanyang Snow," which it claimed was a "toilet preparation simulating their wellknown 'Hazeline Snow." See "Before the Mixed Court," Wellcome Library, Special Collection, WF/ L/06/097. By featuring an announcement within an announcement, BW\&C's announcement illustrates quite literally how the news of the injunction traveled in different forms of English-language media and was meant to be disseminated widely.

${ }^{17}$ The British government had long rendered commercial and legal concerns in China into diplomatic and political issues, using them as pretexts for imperialistic pursuits. It is well documented, for example, how the British presence in China during the nineteenth century was in large part motivated and informed by Britain's desire to avoid and subvert Chinese legal prohibition of opium trading. See Li Chen, Chinese Law in Imperial Eyes: Sovereignty, Justice, and Transcultural Politics (New York, 2016).

${ }^{18}$ The Qing code exhibited some concern with preventing in broad terms unfair economic behavior, such as monopolization and unfair trading. See Robert Heuser, "The Chinese Trademark Law of 1904: A Preliminary Study in Extraterritoriality, Competition and Late Ch'ing Law Reform," Oriens Extremus 22 (1975): 183-210, on 187. But, overall, legal protection for forms of "intellectual property" in imperial China was primarily aimed at bolstering the state's interests in preserving imperial power and maintaining political order and social stability, rather than protecting private interests and ownership. See William P. Alford, To Steal a Book Is an Elegant Offense: Intellectual Property Law in Chinese Civilization (Stanford, Calif., 1995), esp. 24-5. In terms of protecting private marks, however, formal codification of state protection was relatively absent.
} 
century found their products quickly and deftly counterfeited. To protect their trade names, foreign merchants and their governments began pressing for reform in China's commercial law. ${ }^{19}$

Britain led the charge. As its merchants and traders muscled their way into the Chinese market in the late nineteenth and early twentieth centuries, it increasingly placed pressure on successive Chinese governments to draft regulations to police counterfeit trademarks. With the Qing state on its last legs and intellectuals and reformers questioning all aspects of the regime's past in terms of "what went wrong," Chinese reformers came to believe that the very concept of law in China had to be changed to appear to adhere more closely to Western legal standards (many of which were themselves evolving). These reformers worked with successive early Republican states in the face of imperialist pressure to codify trademark infringement and establish a sense of legal equivalence with the West, which at the time was regarded as superior. ${ }^{20}$ China's first complete trademark law was drafted in 1923 and served as the basis of the Nationalist government's law until 1930, when the Nationalists offered their own revision of the trademark law.

It was in this context that BW\&C's identification of Chinese copycats took place and gained momentum. For an example of how the company targeted Chinese merchants, consider its 1922 announcement regarding the Chinese Fo Meng Factory of Ningbo. The announcement started with the heading "Warning" and then featured a translation of the Chinese factory's apology:

\author{
Warning
ANOTHER “'HAZELINE’ SNOW” IMITATION SUPPRESSED \\ 20,000 Chinese labels, 5,000 Foreign labels, 1,000 cartons-DESTROYED! \\ TRANSLATION OF APOLOGY \\ I, R. B. King, representing the Fo Meng Factory of Ningpo, do hereby \\ promise and guarantee that the said firm will not produce any label, carton or \\ circular in connection with their product which in any way resembles or imitates \\ the Designs or Trademarks used or registered by BURROUGHS \\ WELLCOME \& CO. for their well-known products. \\ Dated this $11^{\text {th }}$ day of February, 1922 \\ (Signed) R. B. WILLIAM KING. \\ We prosecute offenders rigorously in the interests of the trade, \\ the public and ourselves ${ }^{21}$
}

With the apology, BW\&C not only secured a public declaration that the company would never imitate its designs but also reminded the English-reading public that it

\footnotetext{
19 Alford, To Steal a Book (cit. n. 18), 34-5.

${ }^{20}$ The first registered marks were with the Imperial Maritime Customs, but since customs was unable to enforce these registrations, the British Foreign Office pressed the matter during negotiations over the Boxer Uprising protocols. A series of commercial treaties seeking to deal with protection of foreign marks followed at the turn of the twentieth century. By 1904, the Qing government promulgated a set of provisional regulations in accordance with British demands, titled "Experimental Regulations for the Registration of Trademarks." These regulations were to be the foundation of the trademark code slotted for future codification, which British and other imperialist powers pushed for into the Republican period. See Heuser, "Chinese Trademark Law" (cit. n. 18).

${ }^{21}$ See the announcement titled "Audacious Fraud Exposed," n.d., Wellcome Library, Special Collection, WF/L/06/097; emphasis in the original. This announcement is undated, but it is filed between an announcement regarding a Parisian copycat issued on 7 February 1922 and one featuring a German counterfeiter issued on 7 March 1924. The one featuring "Chinese gangs" probably appeared sometime between these two.
} 
was the sole owner of this trademark, and that it had disciplining mechanisms with which it could deter potential copycat companies. With the statement in boldface type, BW\&C sought to portray itself as not merely acting out of self-interest, but in fact representing the interests of fair trade, and the consuming public.

BW\&C also pursued more illicit entities, and again, Chinese actors served as powerful examples. The first epigraph at the beginning of this essay comes from a BW\&C announcement that specifically cites BW\&C's prosecution of "audacious fraud" by a "gang of Chinese" engaged in "[a] most elaborate fraud, in which pots, labels and advertising matter were slavishly copied." 22 It identified the vague entity of "gangs" to remind readers of BW\&C's capacity to investigate and convict such illicit conspirators. Just as important, of course, was its promotion of BW\&C as the rightful owner of the lawful and "authentic" trademark (fig. 2). The announcement sought to authenticate the registered trademark "Hazeline' Snow" as a BW\&C product, and not that of dubious actors, arguing that not only the owners of the "Hazeline' Snow" trademark (i.e., BW\&C, which was invested in the prosecution of those who fraudulently used the mark), but also traders and customers who purchased the "real" product wanted this clarity.

From these announcements one can detect the on-the-ground copying that had prompted $\mathrm{BW} \& \mathrm{C}$ to begin policing infringement. That such in-house policing was even necessary speaks to what were fairly nascent disciplinary mechanisms of brand enforcement both in Great Britain and beyond. Chinese counterfeiters were hardly alone. Among the copycats identified in this archive of BW\&C announcements, a number were Western. Local British ones were the most numerous, a few were German and French, and one was Canadian. Among those from outside Europe, alleged offenders from India were most numerous, and except for one from South Africa, the rest were East Asian, with Chinese cases being most numerous. ${ }^{23}$ Yet if copying was spread around the world, China stood out for its "egregious" infringement. The nature of China's treaty ports, where multiple yet fragmented imperialist powers coexisted alongside weak, if intact Chinese sovereignty, might very well have allowed for substantial Chinese copying of Hazeline Snow. And in subsequent years, Chinese copycat soap and cosmetic companies were to continue to be a thorn in the sides of British pharmaceutical firms like BW\&C. ${ }^{24}$ It was for these reasons that Chinese counterfeiters provided a colorful example of unlawful, fraudulent copiers and came to be deemed illicit and deleterious. As such, Chinese copiers could be placed in sharp contrast to the lawful commercial merchant that recognized the authenticity and sole corporate ownership of certain marks, an ideal that BW\&C was invested in establishing in both far-flung markets and the heart of the British metropole.

\section{FRAUDULENT APOLOGIES AND CHINESE AGENDAS}

At first glance, these BW\&C announcements might appear to indicate considerable BW\&C sway over Chinese actors. But, when read carefully, they shed light on how trademark infringement cases became opportunities for Chinese actors to pursue their

\footnotetext{
22 Ibid.

${ }^{23}$ It is not surprising that the largest number of offenders came from India and South Africa. These were direct colonies and easy markets for BW\&C to police.

${ }^{24}$ Lean, "Marking and Copying" (cit. n. 11) discusses some of these cases from the 1930s.
} 
The registered Trade Mark “"Hazeline' Snow” is a brand which denotes specifically a Burroughs Wellcome \& Co. product. The substitution of goods of other manufacture is an infringement and unlawful. Offenders are prosecuted rigorously in the interests of trader, customers and the owners of the Trade Mark.

\section{“HAZELINE' SNOW"}

(Trade Mark)

Original and supreme non-greasy toilet preparation. A product whose exceptional purity and delicate fragrance win permanent customers everywhere.

THE AUTHENTIC PACKINGS

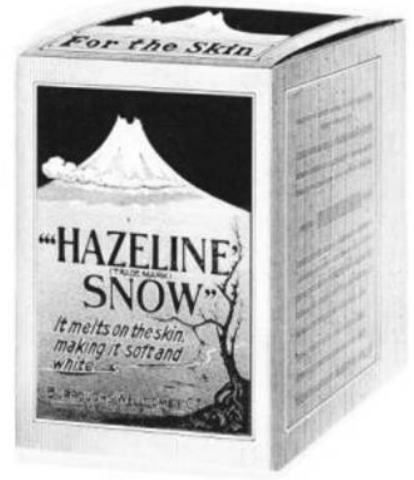

Vanishes without

leaving a trace of

greasiness

Figure 2. The visual of the Hazeline Snow packing comes from a 1910s Burroughs Wellcome brochure and is not the same as the one in the original announcement. See http://www .cosmeticsandskin.com/aba/hazeline-snow.php (cit. n. 4).

own agendas. Take, for example, one 1918 case: a Shandong official turned being forced to issue a proclamation against Chinese merchants selling counterfeit products into an opportunity to assert an anti-Japanese agenda. In a fierce fight between British and Japanese governments over mastery of the Chinese import trade in the early twentieth century, the British came to consider Sino-Japanese counterfeiters to be a real threat between 1913 and 1923 and sought to target both Japanese manufacturers and cooperative Chinese merchants for trademark infringement. ${ }^{25}$ This context informed BW\&C's

${ }^{25}$ For more on Anglo-Japanese negotiations over counterfeiting in China and the emergence of Chinese trademark law, see Eiichi Motono, "Anglo-Japanese Trademark Conflict in China and the Birth of the Chinese Trademark Law (1923), 1906-26," East Asian Hist. 37 (2011): 9-26. Heuser also discusses the long history of Western complaints about Japanese imitations of foreign goods (i.e., Western goods) in China, and about the failure of the 1904 trademark regulations to address non-Chinese infringement of Western marks in China; see Heuser, "Chinese Trademark Law" (cit. n. 18), 190, 199. He argues that these regulations favored the Japanese, who were in fact advisers to the Chinese drafting the regulations, and that this fact was particularly bothersome to Western merchants, who felt disadvantaged in trade as a result (201-3). 
bare-knuckle commercial diplomacy in its prosecution of Hasoda, Matsui, Imayeda \& Co. for selling fraudulent Hazeline Snow in China. In April 1918, BW\&C succeeded in prosecuting the Japanese firm through the Japanese Patent Tribunal and then proceeded to print the following public announcement:

A Japanese imitation of “'Hazeline' Snow” was offered for sale in China. In preparation for foisting this despicable fraud upon the Chinese and in an endeavor to legalise it, the infringers effected registration of the three trade marks here shown.... The fictitious name "Nippon Toilet \& Co.," it will be observed, is slavishly followed by the addresses which indicate the Foreign and Colonial Houses of B. W. \& Co. ${ }^{26}$

Even as BW\&C claimed that the Japanese imitation product was harming the Chinese public, this announcement proceeded to target not only the Japanese counterfeiters, but also Chinese merchants who were selling the allegedly fraudulent merchandise. It worked "with the assistance of one of H. B. M. Consuls" to take local action and convinced the Chinese Special Commissioner for Foreign Affairs in Shandong to crack down on Chinese trade of the Japanese counterfeit.

Since China's defeat in the Opium Wars in the mid-nineteenth century, the unequal treaty system meant that imperialist powers could muscle their way into China's markets with legal, political, and commercial privilege. By the early twentieth century, national humiliation in the face of economic imperialism had reached a fever pitch, and patriotic consumption had become an imperative, with boycott movements against imperialist powers gaining momentum. Patriotic Chinese consumers, aware of how Western merchants had long put pressure on Chinese officials to yield to their wishes, no doubt found this announcement infuriating. Seeking to crack down, the British ensnared Chinese merchants as well as the original Japanese counterfeiters and forced a Chinese official to condemn the Chinese merchant shops. Such actions only reinforced the sentiment that within the fragmented environment of China's treaty ports, where non-Chinese copycat companies were at work and multiple imperialist powers were present, profound humiliation and exploitation of the Chinese could occur.

In a follow-up announcement titled "A Japanese Imitation," a proclamation by the Special Commissioner for Foreign Affairs in Shandong was published, in which Commissioner Tang offered a condemnation of both Japanese counterfeit manufacturers and Chinese merchants. At first blush, this passage might be cited as a humiliating example of a Chinese official submissively accepting blame for the putative wrongdoing of the Chinese merchants. Yet when read more carefully, we can see how the proclamation reveals an agency on the part of the Chinese Special Commissioner that was complex and strategic. The commissioner's statement reads as follows:

WHEREAS in accordance with instructions issued by Board of Commerce and by the Governor several proclamations have been issued prohibiting Chinese from ... the sale of goods with fraudulent trade marks, ... .

AND WHEREAS I have received a dispatch from the British Consul at Tsinan stating that the British firm of Burroughs Wellcome \& Co., of Shanghai, accuse four Tsinan shops ... of selling imitations of their Company's " "Hazeline' Snow,"

\footnotetext{
${ }^{26}$ See the announcement titled "Before the Japanese Patent Tribunal: Burroughs Wellcome \& Co. versus Hosoda, Matsui, Imayeda \& Co.," n.d., Wellcome Library, Special Collection, WF/L/06/097. This document is undated, but the patent trial, the announcement notes, took place on 30 April 1918, and the announcement was most likely printed shortly thereafter.
} 
AND WHEREAS I . . carefully examined the proprietors of these four shops, all of whom bore witness that they had bought the imitation products in other ports and had no intention of imitation foreign trade marks with a view to deceive their customers; . . . and solemnly warned them against continuing in their evil ways;

NOW recently ... the Chinese tradesman not noticing whether the article was genuine or imitation has also been deceived and ordered a stock of such goods for sale, thereby not only injuring the genuine article to a great degree, but also bringing discredit on Chinese trade ...

... A Special Proclamation: (Signed) T'ANG K'O SAN, Concurrently appointed . . . as Special Commissioner for Foreign Affairs in Shantung. ${ }^{27}$

In a period when China was struggling against imperialist incursions, Chinese officials like Tang, who aligned themselves, at least on the surface, with the trademark law, served to endorse the ideological argument that trademark enforcement was an effective mechanism for reducing confusion in the marketplace. By doing so, they appeared to play into the hands of the British by attempting to leverage the latter's rigorous enforcement of IP law in their own conflicts with Japanese importers. Yet at the same time, this announcement became an opportunity for the Chinese commissioner to pursue a rather complicated agenda. By recounting how he personally went to the four shops to investigate the situation and warned the shop owners "against continuing in their evil ways," Commissioner Tang was seeking to demonstrate his authority and efficacy as an administrator who was able to discourage the sales of imitation pieces in Chinese shops, even if he was effectively sanctioning the principle that infringement had to be policed. Where a more obviously subversive tone emerges is midway through where the passage shifts toward defending the Chinese merchants by claiming that they were actually victims who had been duped by the original counterfeiters, the Japanese. With the phrase, "the Chinese tradesman not noticing whether the article was genuine or imitation has also been deceived ... thereby not only injuring the genuine article to a great degree, but also bringing discredit on Chinese trade," the Commissioner portrays the Chinese tradesmen as being guilty at most for their naïveté. He establishes the injury and deception done to them. The Chinese merchants were victims, and Japanese manufacturers were the true perpetrators.

The fact that it was a Japanese merchant company that was the original counterfeiter, and that the location of the counterfeiting was Shandong, made the case particularly fraught and Commissioner Tang's assertion compelling. Three years earlier, in 1915, with the outbreak of World War I and the weakening of Germany's hold in North China, Japan had issued the 21 Demands to the Chinese government. A subset of these demands allowed Japan to expand its sphere of influence into the railways and major cities of Shandong. The public was outraged when Yuan Shikai's government acquiesced to Japanese demands. In June 1919, Shandong was completely ceded to the Japanese by the Treaty of Versailles. News of this development sparked modern China's most iconic

\footnotetext{
${ }^{27}$ See the announcement titled “A Japanese Imitation of One of Burroughs Wellcome \& Co.'s Packings," n.d., Wellcome Library, Special Collection, WF/L/06/097. The special commissioner was appointed by the Ministry of Foreign Affairs. The longer quotation describes the array of institutional mechanisms that were already on the ground policing trademark violation in China. The Board of Commerce and the governor of Shandong were portrayed here as having dispensed instructions prohibiting sales of products with offending trademarks. BW\&C had also deployed diplomatic dispatches from the British Consul in the Shandong city of Jinan to put pressure on the commissioner directly. Finally, the announcement mentioned the Shanghai Custom House, which was where trademarks were registered.
} 
modern political movement, the May Fourth Movement. By this time, Japan's “influence" in Shandong was keenly felt, and this case of a Chinese official being forced to kowtow to Western demands for violations committed by the Japanese would have been particularly volatile. Given the specific colonial situation in Shandong, the text cleverly used the occasion to evoke popular sentiment that the Chinese once again were victims of Japanese counterfeiting and related excesses.

Even as he faced inhospitable relations of power vis-à-vis British imperialists, Tang was not merely acceding to BW\&C's wishes. His voice here was far more nuanced. He sought to bolster his official status by displaying his ability to handle the case effectively as well as to use this proclamation to promote an image of an efficient Chinese officialdom in bringing order to the affair. He deftly directed attention away from the Chinese shop owners to the Japanese, whom he sought to portray as the real offenders. Finally, one wonders whether the apology was not simply a pro forma matter that once taken care of had little influence on actual commercial practice. The commissioner's apology could well have been nominal and meant to appease BW\&C. It could have forestalled any real concessions or allowed the Chinese commissioner to avoid engaging in concrete efforts to crack down on alleged offenders. Indeed, even while seeking to exhibit BW\&C's ability to discipline imitators worldwide, much in these announcements points to a rather turbulent situation. These announcements likely served more as an indication of how BW\&C felt it was necessary to respond to something not quite yet under its control, rather than a sign of any success in containment.

BW\&C not only fought counterfeiting via English-language announcements. The company also sought to target Chinese audiences directly by publishing in Chinese media sources. Take, for example, the full-page ad for Hazeline Snow that appeared in the January 1915 issue of the Ladies' Journal (Funü zazhi). Splashed across the top of the ad was “"HAZELINE' 夏士蓮雪花 SNOW” in large block letters. Smaller block letters for "TRADEMARK" and shangbiao 商標, the Chinese characters for trademark, bookended the large “'HAZELINE” 夏士蓮雪花 SNOW” to indicate that it was a genuine trademark. The bottom part of the ad included the image of the trademarked container used to package Hazeline Snow and detailed copy in Chinese, which touted the virtues of the cream for the skin as well as its medicinal functions. The copy also warned readers and potential consumers about fakes, letting them know how to distinguish the genuine cream and trademark from fraudulent versions. It informed the consumer what the original should feel like when used and also how to recognize the "lofty decoration" that was most elegant, whereas both the feel and the packaging of counterfeit products could not be more divergent. Finally, the bottom left corner of the ad included a voucher that the reader could cut out and mail in for a lengthier booklet that would explain in detail how to distinguish the genuine product from fakes. The ad is remarkable for the lengths to which it went to explain how to identify fraudulent brands. Notably this ad appeared in a journal that published articles (which I discuss below) that provided specific information for non-BW\&C manufacturers wanting to make their own versions of Hazeline Snow, the very fakes against which the ad was warning. ${ }^{28}$

We need to keep in mind that internally, China was not simply a site uniquely teeming with unethical counterfeiters and hapless officials. Different views and practices of copying marks existed domestically, as Chinese themselves grappled with changing

\footnotetext{
${ }^{28}$ See the discussion of Shen, "Method for Manufacturing Cosmetics" (cit. n. 2) in the next section.
} 
ideas about what ownership of a brand might mean. With the chaos that characterized the early Republic, the central Chinese state was not particularly interested in or able to (should it even want to) enforce trademark legislation that was only gradually being drafted into code. We saw with Commissioner Tang the conditions under which a provincial level official might have at least superficially cracked down on infringement. At the local level, nonstate entities often stepped into the vacuum created by a distracted state to promote trademark enforcement, often to their own advantage. Take, for example, pharmaceutical industrialist Chen Diexian (1879-1940), a powerful Shanghai editor and leading cosmetic industrialist. Chen's most famous product was Butterfly Brand tooth powder, unique in its ability to double as face powder. As the Butterfly Brand took off, copycat brands quickly emerged. Chen sought to crack down through a variety of methods, including notably using his access to the media as a bully pulpit. He published notices that identified alleged counterfeits of his "Butterfly" trademark in key journals, such as the Jiangsu Industrial Monthly.$^{29}$ In these pieces, Chen underscored the role of provincial level state agencies in institutionalizing trademark enforcement, described new institutional apparatus for policing trademark ownership, and outlined in elaborate detail how these agencies pursued alleged counterfeiters. Much like the BW\&C announcements discussed above, these notices sought to shame domestic companies into abiding by these new practices of enforcing corporate ownership over trademarks. They also functioned to spur local officials to act and pursue copycats. As domestic Chinese manufacturers saw their trademarks, recipes, and manufacturing processes disseminated, the emerging trademark regime became a useful means for them to stave off potential adapters.

\section{CIRCULATING RECIPES: “COMMON KNOWLEDGE” OR TRADEMARK INFRINGEMENT?}

Just as marks spread worldwide, so too did recipes, trade secrets, and formulas for manufacturing branded commodities. Emerging manufacturers around the world (and not just in China) sought access to manufacturing processes of successful brand-name items, and those who were manufacturing successfully increasingly became wary of the spread of their formulas. The recipes and ingredients of Hazeline Snow circulated globally in pharmaceutical gazettes at the turn of the twentieth century, and by the 1910s were being translated and compiled into Chinese and printed in China's periodical press. BW\&C thus employed trademark laws to accuse alleged copiers of infringing upon their brand (given the simplicity of products like Hazeline Snow, their recipes and formulas were not protected by patent laws). They sought to stem what they saw as fraudulent circulation of their recipes, both on the periphery and in the metropole, and curb the possibility of what some today might call industrial espionage.

Circulation of manufacturing know-how was not always a matter of legal or ethical violation in early twentieth-century China. Even as some Chinese manufacturers were starting to support the crackdown on trademark violation led by foreign companies

\footnotetext{
${ }^{29}$ See, e.g., Zhang Yi'ou, ed., "Shanghai jiating she Wudipai camian yanfen jiamao yinggai gai gan weibian" [Shanghai Household Industry Peerless Brand Face and Toothpowder trademark cannot be copied], Jiangsu shiyeyuekan [Jiangsu industrial monthly] 29 (1921): 44-5. For a closer analysis of this particular notice, see Eugenia Lean, "The Butterfly Mark: Chen Diexian, His Brand, and Cultural Entrepreneurism in Republican China," in The Business of Culture: Cultural Entrepreneurs in China and Southeast Asia, 1900-65, ed. Christopher Rea and Nicolai Volland (Vancouver, 2014), 62-91, esp. $80-2$.
} 
like BW\&C, just as many heralded such shared information as "common knowledge" necessary for strengthening the nation (including some of the very same individuals arguing for trademark laws, including the aforementioned Chen Diexian). The circulation of common knowledge was not only commercially profitable but also deemed virtuous in a period when a movement to buy and manufacture Chinese goods, known as the National Products Movement, was starting to gain momentum. ${ }^{30}$ It functioned to establish a new kind of consumer who read newspaper columns for common knowledge about manufacturing and basic chemistry. By consuming such knowledge, the reader was in a better position to navigate an increasingly fraught capitalist market of pharmaceutical goods, replete with fraudulent and inauthentic goods. The circulation of manufacturing knowledge of brand items clearly defied any legal hegemony of the global trademark law. Whereas IP law notably sought to reduce confusion in the marketplace by arresting circulation (of goods), the emphasis on common knowledge in China did precisely the opposite: it sought to reduce confusion by promoting the circulation of knowledge as well as to undercut capitalist interests of imperialist companies like BW\&C.

As noted earlier, by the late nineteenth century, as modern patent law started to emerge, it soon became clear that simpler manufacturing processes, including those behind daily commodities like vanishing cream, patent medicine, and cosmetics, were often not subjected to patent protection. By the 1880 s, for example, U.S. courts made a distinction between mere recipes or simple formulas, where ingredients retained their discrete characters despite assemblage with other ingredients, and formulas for a specific product that included the manufacturing of new ingredients in the process of making the new product. Patents were granted only in the latter cases. ${ }^{31}$ When this occurred, pharmaceutical companies like BW\&C relied on trademarking to stake a legal claim over their non-patentable manufacturing processes and halt their widespread circulation. Recipes were considered to be part of the brand and trademark and thus subjected to trademark laws.

Such tactics could prove quite effective. Take, for example, the St. Louis-based journal National Druggist, which published an entry on Hazeline Snow and its formula in its August 1907 issue. ${ }^{32}$ The entry noted explicitly that it had been translated from the French journal Journal de Phamacie d'Anvers, speaking to the global transmission of such information. In the December issue, however, the National Druggist published "Hazeline Snow a Trade-Mark, and Name Not Public Property," in which it cited the August issue's inclusion of the extract from the Journal de Phamacie d'Anvers. Essentially a retraction and apology, the announcement states:

Our attention has been called to fact that the title Hazeline Snow is the trade mark Burroughs Wellcome \& Co and hence being their exclusive property can not be employed by any other person or firm. We take pleasure in publishing this notice and we will ask our readers to take care not to use this title to designate any preparation of their own or anybody else's besides that of Burroughs Wellcome \& Co in order that they may avoid the imputation of trade mark infringement and a possible suit for injunction and damages. ${ }^{33}$

\footnotetext{
${ }^{30}$ For more on the National Products Movement, see Karl Gerth, China Made: Consumer Culture and the Creation of the Nation (Cambridge, Mass., 2003).

Gabriel, Medical Monopoly (cit. n. 10), 121-2.

32 "Hazeline Snow, a Toilet Cream," National Druggist 37 (1907): 272.

33 "Hazeline Snow a Trade-Mark, and Name Not Public Property," National Druggist 37 (1907): 411.
} 
BW\&C had learned of the earlier publication of its recipe, had intervened with the threat of legal action, and the National Druggist was forced to publish this notice. ${ }^{34}$

By the 1910s, pieces offering manufacturing tips for Hazeline Snow were appearing in Chinese journals. Featured in a 1915 issue of the Ladies' Journal, the article, "The Method for Manufacturing Cosmetics," argued that women needed to know how to make cosmetics and stated that such knowledge was crucial for the making of the modern household. ${ }^{35}$ To inform the targeted genteel female reader, the piece provided concrete information on how to make a long list of cosmetics. In the entry on vanishing cream, it noted that face cream was a commodity readily available for purchase and identified three brands that dominated the market. Two were Chinese brands, the Three Star Brand (Sanxing) and Shuangmeimo. The third was Hazeline Snow (Xiashilian). ${ }^{36}$ As seen with the second epigraph at the beginning of this essay, the entry divulged that the ingredients for Hazeline Snow included hazeline, stearic acid, glycerin, sodium bicarbonate, and soda water.

To better understand the manner in which the sharing of manufacturing know-how of brand commodities might have been appreciated in early twentieth-century China, it is worthwhile to examine how such knowledge was often deemed "common knowledge." Common knowledge was published in China's burgeoning print media and presented as tasteful knowledge for learned readers to help them navigate emerging capitalist markets for material goods in China. This category of knowledge often included manufacturing information and recipes for trademarked commodities and brands, both domestic and foreign. As such, it was often portrayed as both commodified knowledge and crucial information necessary for building Chinese industry. Take, for example, "Common Knowledge for the Household" ("Jiating changshi"), a column featured in the highly regarded literary supplement, "Free Talk" ("Ziyoutan") in Shanghai's largest newspaper, the Shenbao, that was compiled by Chen Diexian, the manufacturer of Butterfly Brand Toothpowder who also happened to be a powerful Shanghai editor and, ironically, an advocate for the domestic policing of the infringement of trademarks and packaging, especially of his own. Running from 1917 to 1927 , the column featured a wealth of information, including tips on healing different conditions, keeping foods fresh, and maintaining hygiene, as well as science and manufacturing. These tips were digestible yet informative nuggets of knowledge meant to improve everyday life and to be consumed in a leisurely fashion by learned generalist readers of the literary supplement, who might have included merchants, intellectuals, and urbane citizen-readers. Featuring tips on how to manufacture soap, dyes, camphor, matches, bleach, and soy sauce, along with entries on engraving copper plates, welding together aluminum, and producing gadgets such as the chemical foam-based fire extinguisher, the column became known specifically for its coverage of manufacturing and industrial knowledge, along with chemistry and physics. By doing so, the column helped engender a new understanding of the learned Chinese consumer as someone fully capable of evaluating and grasping production and manufacturing technologies.

\footnotetext{
${ }^{34}$ Earlier accounts of how to manufacture Hazeline Snow did not seem to invite similar scrutiny. The 4 December 1897 issue of Chemist and Druggist: The Newsweekly for Pharmacy (51: 884) included a brief description of how to improve Hazeline Snow, and the information was shared without any sense that it might constitute a legal or ethical violation.

${ }^{35}$ Shen, "Method for Manufacturing Cosmetics" (cit. n. 2).

${ }^{36}$ Ibid., 24-5.
} 
"Common knowledge" also appeared in journals that were intended not only for general consumption but also to serve as the basis of emerging expertise. Take, for example, the new-style industry periodical, Huaxue gongyi [The chemical industry journal]. Published from 1922 to 1923 by the Shanghai School of Chemical Industries, this publication regularly presented brand-name recipes and reports on factory and production conditions of famous and emerging companies. ${ }^{37}$ There appeared to be little regard for any sense of exclusive ownership over the manufacturing knowledge or specific formulas and recipes, including for brand and trademarked items, and such knowledge was unapologetically presented as crucial for readers and students to emerge as experts in the chemical industry. The journal featured articles on large-scale manufacturing processes, surveys and reports on factories and companies, as well as pieces on chemical research, some of which included specific information about the production processes of famous brands and companies. Typical titles were "The method to make foreign candles," "Common knowledge in testing soap," and "The general state of Guangxi's manufacturing of cinnamon oil." The article "Common Knowledge Chemists Should Possess" detailed what common knowledge entailed. ${ }^{38}$ Serving the same purpose was an article describing the basic knowledge in cosmetics production that a student needed to acquire, including how to manufacture soap, vanishing cream, tooth powder, scented powders, hair tonic, and perfumes. ${ }^{39}$ Some pieces included recipes for famous brands of cosmetic items, both foreign and domestic. Others featured manufacturing processes of well-known factories. One report was an investigation of the ingredients of Xiangmao soap, a popular British brand. ${ }^{40}$ A review of a visit to the Great Five Continents soap factory described in detail the kind of machinery being used, including the filter press, the automatic soap dryer, milling machines, and the compressor machine. ${ }^{41}$

In the October 1922 issue, the manufacturer of Butterfly Brand Toothpowder, Chen Diexian, found his company's manufacturing processes featured in a detailed survey. ${ }^{42}$ Readers learned the exact steps in mixing Butterfly tooth powder and manufacturing magnesium carbonate, a key ingredient in the tooth powder and other powder-based cosmetics. The piece describes two methods to manufacture magnesium carbonate, providing the exact reaction sequences as chemical formulas in its explication. The first process involved adding sulfuric acid to magnesite powder, which would turn the solution to magnesium carbonate, and then, upon adding water and mixing in sodium carbonate, a sediment that was magnesium carbonate would be produced. The second method described involved the extraction of sodium chloride from seawater to leave magnesium chloride, which the reader is then instructed to mix with sodium carbonate in order to produce magnesium carbonate. These processes were not manufacturing secrets exclusive to the young company, but rather common knowledge that was to

\footnotetext{
${ }^{37}$ The school was an example of vocational education focused on industry and commerce to train and educate lower middle-class youths; such schools were starting to appear in large cities such as Shanghai. For more on the school's goals, curricula, and student requirements, see the advertisement for the school in the inner cover of the October 1922 issue (vol. 1, no. 2) of Huaxue gongyi.

${ }^{38}$ Yu Ziming, "Huaxuejia yingyou zhi changshi" [Common knowledge chemists should possess], Huaxue gongyi 1 (May 1923): 57-9.

${ }^{39}$ Lü Heng, "Yong huazhuangpin yingju zhi changshi" [Common knowledge one needs to use cosmetics], Huaxue gongyi 1 (October 1922): 18-20.

${ }^{40}$ Fang Chaoheng, "Xiangmao pai feizao tian shiliao zhi diaocha" [Investigation of Xiangmao Soap's ingredients], Huaxue gongyi 1 (October 1922): 44-6.

${ }^{41}$ See Huaxue gongyi 1 (May 1922): 49-52.

42 See Huaxue gongyi 1 (October 1922): 41-4.
} 
sow the grounds for the growth of native industry in the face of economic imperialism. Common knowledge was thus hardly a violation, but a precious commodity that was invaluable both for savvy consumers who were skillful in discerning among brands and for adaptive and innovative producers able to compete in the burgeoning pharmaceutical industry.

Precedents for innovative nativist adaptation of foreign technologies and industrial and scientific knowledge for strengthening China can be found in the late nineteenth century. During the Self-Strengthening Movement (ca. 1861-95), the concept of adapting or duplicating [ fangzhi] in the process of weapons production played a key role in the manufacturing pursuits in arsenals erected to strengthen Qing China in the face of unrelenting imperialist encroachment. At the Jiangnan Arsenal, a key arsenal that the Qing state had established as part of the movement, the central task was technological learning and training with the ultimate goal of manufacturing modern armaments. If there was considerable failure at the arsenals, with bombs notoriously failing to explode, they nonetheless were the site of considerable technological transfer, adaptation, and innovation. ${ }^{43}$ Creativity in technological production at the arsenal was heavily dependent upon duplication and emulation [ fangzhi] of Western knowledge and technology. Research at the arsenal, sample making (of parts of a weapon), and testing for efficacy turned on the practice of gaizao, or "remaking," and it was with this process of remaking that creativity and innovation occurred. ${ }^{44}$

By the early twentieth century, with the decline of state-supported Self-Strengthening arsenals and the rise of private light industry in China's treaty ports, the adaptation of foreign technologies to manufacture commodities and daily use objects remained pressing. The "science" behind the manufacturing of commodities such as soap and cosmetics was predicated on basic chemical knowledge, and not particularly challenging. Such knowledge could be transferred quite easily, and little capital was required in the manufacturing of such items. For Chinese merchants and industrialists seeking to build nativist industry, the sharing and strategic adaptation of industrial manufacturing know-how as common knowledge in China's burgeoning mass media was not just unproblematic, but in fact patriotic and urgent. That this manufacturing information was associated with successful brands - both foreign (e.g., Hazeline Snow) and Chinese (e.g., Butterfly Brand) — made their dissemination all the more valuable.

As these recipes started to circulate in Chinese publications, they would have had the effect of exacerbating anxieties about Chinese copying that players such as BW\&C might have already started to feel with the widespread emulation of their marks and packaging. It was no accident that this was around the time that foreign entities started to pursue trademark infringement in China so aggressively. In addition to the aforementioned cases in which BW\&C pursued alleged Hazeline Snow counterfeiters, American lawyer Norman Allman published Handbook on the Protection of Trade-Marks, Patents, Copyrights, and Trade-names in China in $1924 .{ }^{45}$ By the 1930s, his Shanghaibased litigation firm, Allman \& Co., represented British companies in cases of trade-

\footnotetext{
${ }^{43}$ Meng Yue, "Hybrid Science versus Modernity: The Practice of the Jiangnan Arsenal, 1864-1897," EASTM 16 (1999): 13-52. See also Benjamin Elman, On Their Own Terms: Science in China, 15501900 (Cambridge, Mass., 2004), 355-95.

${ }^{44}$ Meng, "Hybrid Science" (cit. n. 43).

${ }^{45}$ Norman Allman, Handbook on the Protection of Trade-Marks, Patents, Copyrights, and Tradenames in China (Shanghai, 1924).
} 
mark infringement in the courts of China. This included representing BW\&C in its attempt to prosecute the Chinese firm, Liya, for counterfeiting the iconic design of Hazeline Snow face cream to sell Liya's Himalaya soap. In another case in 1934, Allman \& Co. was to represent Lever Brothers (China) Ltd. against a certain Li Cheng factory, for allegedly infringing upon Unilever's famous brand marks (the English name "Lux" and the Chinese name for Lux soap, Lishi) along with the packaging and design of Lux soap cartons, to sell its face cream. Although both cases involved the British foreign office seeking diplomatic means to put pressure on the Nationalist regime to discipline the offenders, they did not do so to particularly good effect. Neither saw the light of day in a Chinese courtroom. ${ }^{46}$ Yet despite the failure to prosecute the alleged Chinese copycat firms, both were indicative of the continued vigilance and aggression with which BW\&C and other pharmaceutical companies based in the West employed modern trademark law to pursue Chinese adaptation of marks and recipes.

\section{CONCLUSION}

Much writing on the history of IPR has tended either to focus solely on the West or to start with the assumption that the modern regime of intellectual property originated wholly in the West and was then exported to the rest of the world. ${ }^{47}$ China scholars, too, have tended to see the emergence of the formal legal treatment of trademarks as property in China as uniquely modern and originating from abroad. William Alford, for example, argues that intellectual property rights had not developed indigenously in imperial China because of its particular political culture, which focused not on ownership and private interest but on political order and the preservation of imperial power. ${ }^{48}$ In contrast, this piece has adopted a global approach and assiduously avoids viewing the modern trademark as "Western" and seeing China playing a "catch-up" role, lagging behind the West in its efforts to erect a modern property rights regime. It takes seriously how Chinese actors were active agents in a worldwide debate over the ownership of marks and recipes and the making of a modern property rights regime. Chinese manufacturers, merchants, officials, and editors of industrial journals and magazines were hardly passive and insisted on playing by their own rules. They actively challenged, blithely ignored, and appropriated savvy ideas of ownership that BW\&C and other pharmaceutical companies were seeking to promote. They ingeniously adapted a host of strategies and counterstrategies to adjust to newly emerging logics of trademark infringement in international disputes. As a result, they had a hand in shaping what was hardly a fixed aspect of capitalism in the early twentieth century, defining (if, at times, through acts of resistance or defiance) the parameters of a regime of trademark infringement that was becoming a key legal mechanism of control in modern global commerce, industry, and science.

\footnotetext{
${ }^{46}$ For a discussion of these cases, see Lean, "Marking and Copying" (cit. n. 11).

${ }^{47}$ There is a large corpus of historical scholarship on IPR that focuses on the West. For excellent examples, see the work by Mario Biagoli and his collaborators, including Biagoli and Peter Galison, eds., Scientific Authorship: Credit and Intellectual Property in Science (New York, 2003); and Biagoli, Martha Woodmansee, and Peter Jaszi, eds., Making and Unmaking Intellectual Property (Chicago, 2011). For an example of a study that is global in scope but identifies the rise of modern IPR in early modern Europe and traces its exportation to the rest of the world into the modern period, see Johns, Piracy (cit. n. 10).

${ }_{48}$ Alford, To Steal a Book (cit. n. 18).
} 
This essay converges with several contributions in this volume that place transnational entanglements at the forefront of their analysis of modern science and capitalism. It is similar, for example, to Sarah Milov's essay in its concern with showing how uneven power relations in the twentieth century that seemingly favored Western capitalist corporations often resulted in unintended consequences. ${ }^{49}$ Milov illustrates how even as American tobacco companies helped constitute the "Japanese smoker," data based on wives of Japanese smokers, served as the basis of a transnational grassroots regulatory movement against American tobacco. In a similar vein, this essay sheds light on how even as BW\&C sought to constitute the "Chinese copycat," Chinese copying served to impose and expose limits to BW\&C's attempts to erect an effective global trademark infringement regime. The powerful corporation was not fully able to advance purportedly "universal" views of corporate ownership of trademarks and recipes as widely as it would have liked.

With this in mind, this essay argues for a more refined understanding of the motif of circulation that takes into account the historical contingencies behind the transmission and travel of knowledge and things, and their obstruction. Conventional accounts of modern science often take as a given that Western science was built on a foundation of openness, sharing, and transparency. Proponents of capitalism similarly make the ideological claim that a core trait of capitalism is free and open markets. Here, however, we see how "common knowledge," unapologetically commercial and derivative in its inclusion of domestic and foreign brand recipes and manufacturing tips, helped expose the hypocrisy behind purportedly ethical claims of both the universal nature of modern science and the ideal of the free market promoted by advocates of modern capitalism. Chinese compilers, editors, and readers found common knowledge, manufacturing and chemical information shared by all alike and hence owned by no one in particular, to be invaluable. The shared knowledge was to arm the new Chinese consumer with simple yet crucial manufacturing and chemical knowledge necessary to navigate a burgeoning and treacherous domestic market of pharmaceuticals filled with questionable products. It was also intended for emerging Chinese manufacturers who were seeking to compete in domestic and global pharmaceutical markets. Common knowledge and Chinese copying of marks defied the ideals of ownership being pursued by advocates of the new IP regime. Deeply troubled, Western corporations aggressively deployed trademark law to discourage the spread of trade names and brand recipes. As noted in the introduction to this volume, recent trends in the history of science that have focused on the global movement of knowledge in the making of modern science have generated an overly rosy picture of the seamless circulation of knowledge in the making of science, which serves to reinforce the neoliberal claims of "universal" scientific knowledge and free and open capitalist markets. In contrast, this essay provides us with a powerful instance of how modern IP functioned to arrest circulation flows, exploring how this occurred and why.

Finally, this essay has shed light on the manner in which China's reputation as a brazen copier might have emerged. While hardly unique in its copying, Chinese adaptation of Hazeline Snow's marks and the circulation of its recipe were savvy and often tremendously successful. This success invited attention and vitriol, and BW\&C condemned Chinese copiers as ethically dubious and particularly venal in behavior. Such

${ }^{49}$ Sarah Milov, "Smoke Ring: From American Tobacco to Japanese Data," in this volume. 
condemnation helped ensure that the Chinese copycat would emerge as an iconic counterfeiter. This reputation persists to this day, as Chinese manufacturers are regularly accused of manufacturing knockoff Gucci handbags or fraudulent versions of the iPhone. Hallam Stevens's article in this volume troubles the easy distinction between imitation and innovation in such an argument by showing how copying and innovation go hand in hand in contemporary Shenzhen. ${ }^{50}$ Similarly, this essay shows that the assumption that the two-imitation and innovation - are mutually exclusive has a long history and was created by European manufacturers over time to protect their capital by slowing down the free circulation of things and ideas into China. Chinese adaptation of brandname items continues to generate global anxiety today, which, in turn, continues to engender claims that China can only copy and not innovate. This twenty-first-century reality only makes the historical investigation into the making of the Chinese copycat in the early twentieth century, and its crucial entanglement with the rise of global commerce, science, and modern imperial power, all the more urgent.

${ }^{50}$ Hallam Stevens, "Starting up Biology in China: Performances of Life at BGI," in this volume. 